\title{
Benefits of crenotherapy in digestive tract pathology (Review)
}

\author{
MAGDALENA DUMITRESCU ${ }^{1,2}$, MADALINA GABRIELA ILIESCU ${ }^{3 *}$, LAURA MAZILU $^{4}$, \\ SERGIU IOAN MICU ${ }^{5}$, ADRIAN PAUL SUCEVEANU ${ }^{5 *}$, FELIX VOINEA ${ }^{6}$, \\ CLAUDIA VOINEA $^{7}$, ANCA PANTEA STOIAN ${ }^{8}$ and ANDRA-IULIA SUCEVEANU ${ }^{5}$ \\ ${ }^{1}$ Doctoral School, 'Ovidius' University of Constanta, Faculty of Medicine, 900527 Constanta; \\ ${ }^{2}$ Department of Physical Medicine and Rehabilitation, Balneal Sanatorium of Mangalia, 905500 Mangalia; \\ ${ }^{3}$ Department of Physical Medicine and Rehabilitation, Balneal and Rehabilitation Sanatorium of Techirghiol, \\ 906100 Techirghiol; Departments of ${ }^{4}$ Oncology, ${ }^{5}$ Gastroenterology, ${ }^{6}$ Urology and ${ }^{7}$ Endocrinology, \\ County Clinical Emergency Hospital of Constanta, 900591 Constanta; ${ }^{8}$ Department of Diabetes, Nutrition and \\ Metabolic Diseases, 'Carol Davila' University of Medicine and Pharmacy, 050474 Bucharest, Romania
}

Received September 1, 2021; Accepted October 1, 2021

DOI: $10.3892 /$ etm.2021.11045

\begin{abstract}
Balneotherapy, a branch of physical and rehabilitation medicine using the natural factors of balneal resorts for therapeutical purposes to modulate the symptoms of numerous diseases, represents a non-pharmaceutical therapeutic alternative, easily accepted by patients and used both preventively and curatively. Crenotherapy, a branch of balneotherapy, is the method in which mineral waters are used as a therapeutic internal cure by ingestion. This procedure is performed in spa resorts (where these natural resources exist), and the ingestion of mineral water takes place at the source (spring), in the quantities recommended by the medical rehabilitation physician, according to specific regimens for the condition to be treated. Depending on their physical and chemical composition, the therapeutic mineral waters fall into several categories, having clear indications for certain pathologies. Hypotonic, isotonic, or slightly hypertonic mineral waters are recommended in diseases of the digestive tract and hepatobiliary conditions. Over time, studies have been conducted to determine the effect of these types of treatments, highlighting the complex influence of crenotherapy on the gastrointestinal tract, with favorable
\end{abstract}

Correspondence to: Dr Sergiu Ioan Micu, Department of Gastroenterology, County Clinical Emergency Hospital of Constanta, 145 Tomis Boulevard, 900591 Constanta, Romania

E-mail: micuioansergiu@yahoo.com

Professor Laura Mazilu, Department of Oncology, County Clinical Emergency Hospital of Constanta, 145 Tomis Boulevard, 900591 Constanta, Romania

E-mail: lauragrigorov@gmail.com

${ }^{*}$ Contributed equally

Key words: mineral waters, crenotherapy, digestive tract diseases, alkaline, oligoelements, ulcer results, therefore the use of mineral water intake in various pathologies being recommended. The current review focuses on the existing literature data and refers to the main progress made in understanding the benefit, indications, and crenotherapy procedures in the management of gastrointestinal disorders.

\section{Contents}

1. Introduction

2. Pathogenic background for crenotherapy usage

3. Evidence-based literature data focused on the benefit of crenotherapy for GI (gastrointestinal) tract pathologies

4. Conclusions

\section{Introduction}

As therapeutic tools, mineral waters are most frequently used as internal cure (crenotherapy) and also in the external cure, using various individualized techniques based on the type and stage of the disease or based on the patient's response and co-morbidities (1).

In Antiquity, on the Dacian territories, the Geto-Dacian population founded settlements in the vicinity of the natural springs (Utidava, Petrodava), which were used for therapeutic purposes, upon the indications of the priests. There are documents attesting that 2500 years ago, Herodotus recommended the 21-day cure of mineral water, a fact scientifically confirmed only in the twentieth century (2).

Over time, many digestive pathologies have been referred to obtain the beneficial effect of crenotherapy; even the term and the beneficial link were later defined. The impact on the digestion pathways, on the peristalsis, or the potential antiseptic effect of some mineral waters raised the interest for improving different pathological situations (3). Physicians are already trying to add their possible effects to current pharmacologic or surgical treatments, considering that balneal treatments can 
provide a noninvasive way that can improve the quality of life in many cases (4).

In 1924, in Bucharest, A. Teoharia was the first researcher preoccupied with the physicochemical properties of mineral waters and their benefits on human health. This research was later published in 1929 in Somes Archive by the writer Virgil Sotropa, which presents the popularity of these natural resources in different pathologies, including gastritis and bile or liver diseases (5). During the second half of the twientieth century, the therapeutic effects of mineral waters of Romania were scientifically confirmed, some of them being recommended for use as crenotherapy of digestive and hepatobiliary tract diseases (6).

Most countries benefitting from natural springs of mineral waters have undertaken research in terms of the physicochemical composition and also on the effects of mineral waters, identifying the uses of various types of mineral water for specific pathologies. In 2009, a centralized classification of mineral waters was performed, according to European legislation (1). Thus, the main categories are bicarbonate-rich, sulphurous, chloride, high-calcium, high-magnesium, fluoridated, and ferruginous (chalybeate) mineral waters $(1,7)$.

Mineral waters, based on biological activity, can be classified as: cathartic waters, diuretic waters and waters with antiphlogistic properties (8).

This article reviews the clinical studies conducted in the last five years on the effect of mineral waters in gastrointestinal disorders, using data from the MEDSCAPE and PubMed portals; 9 eligible studies were identified (Table I).

\section{Pathogenic background for crenotherapy usage}

There are certain chronic diseases of the digestive and hepatobiliary tract, for which spa treatment, including crenotherapy with mineral waters, can contribute to a better result, by complementing the effects of basic dietary, pharmacological and surgical therapies. The mineral waters used in the internal cure represent, in fact, a non-pharmacological therapy, considering the natural, albeit pharmacological resource, based on their chemical content.

Thus, depending on their composition, there are indications of therapeutic cures in which simple alkaline or bicarbonate waters are used. These contain at least $1 \mathrm{~g}$ of salts/liter, with the predominance of bicarbonate ion bound to $\mathrm{Na}$ and $\mathrm{K}$ cations. The effects of these waters on the digestive tract reside in the action of $\mathrm{Na} / \mathrm{K}$ bicarbonate, an alkaline substance, confirmed by studies carried out by specialists from spas and the National Institute for Rehabilitation, Physical Medicine, and Balneology $(1,5,9)$. The ingestion of these waters reduces the chlorhidropeptic secretion (when ingested an hour and a half before a meal) or stimulates it (administered during a meal), also affecting gastric motility and bile ducts, such as fluidization of the bile, depending on the method of administration. In Romania we provide this treatments in Slanic Moldova and Sangeorz Bai balneary resorts $(1,6,9)$.

Another category, alkaline-earth sodium bicarbonate, high-calcium, and high-magnesium waters have an excitation effect on gastric secretion (Calimanesti-Caciulata, Slanic Moldova) through the predominance of $\mathrm{CO}_{2}, \mathrm{NaCl}, \mathrm{H}_{2} \mathrm{~S}$, or sulfates $(1,5)$.
Sulfurous waters (Baile Olanesti, Calimanesti-Caciulata, Mangalia, Herculane) stimulate gastric secretion, are choleretic, cholecystokinetic, gastric, and intestinal motor stimuli. Hydrogen sulfide regulates the function of biological systems and plays a vital role in various systems and diseases (9).

The hydrogen sulfide present in these waters is responsible for the stimulating effect on the enzymatic and metabolic processes in the gastrointestinal mucosa, stimulating the chemoreceptors, a fact that has been experimentally confirmed (1,7,9-11). Depending on the chemical composition of different sulfur waters, their effect on the digestive tract is different, as follows: poorly mineralized sulfur waters (Mangalia, Baile Olanesti springs 10 and 24) stimulate gastric secretion initially, a stimulation followed by an inhibition phase; those from Caciulata spring 1 (one) and Calimanesti spring Pausa 1 and 2 have a stimulating effect on the gastric secretion, those from Calimanesti spring 1 stimulate secretion after an initial phase of inhibition, and those from Baile Olanesti springs 5, 7 and 12 inhibit secretion (1).

Oligoelements play essential roles in the metabolism and function of the gastrointestinal and renal tract (12). In sodium, magnesium, and calcium sulfate waters, the effects are choleretic, cholecystokinetic and laxative (Amara, Baltatesti, Nicolina-Iasi). Mineral calcium and magnesium sulfate waters are confirmed to have ahypoglycemic and lipid-lowering action. They may be used as alternative therapeutic approaches of metabolic syndrome and mild forms of diabetes mellitus, preventing progression to disabling complications, such as diabetic retinopathy of diabetic foot $(13,14)$. The effects on the secretion of the stomach are different, depending on the complexity of the chemical composition: the water from Amara decreases gastric secretion. At the same time, that of Bizusa spring 1 intensely increases the secretion and acidity of gastric juice $(1,5)$.

Chlorosodium waters used as internal treatment are hypotonic or isotonic waters, with concentrations below $10 \mathrm{~g}$ $\mathrm{Na} \mathrm{Cl} /$ liter. These stimulate gastric and intestinal secretion, activating digestive enzymes (pancreatic-intestinal amylase), increasing gastrointestinal peristalsis reflexively, the elements present in these waters stimulating the vagus nerve $(1,6,9)$.

The indications regarding the dosage and the administration method are individualized and depend on the patient's condition and the experience of the physician (5). The choleretic effect is helpful in biliary dyskinesia but must be used with caution in patients with biliary microlithiasis, being a possible trigger for calculous migration and cistic or common bile duct (CBD) obstruction, responsible for acute cholecystitis and angiocholitis, which requires rapid surgical treatment $(15,16)$. The potential harmful effects of sulfate waters may lead to increased transaminases in vulnerable subjects, thus is contraindicated in patients with hepatitis (17). The comprehensive medical history and the complete clinical evaluation of the patient before crenotherapy indication are imperative. The benefits, the potential side effects, and therapeutic alternatives should be considered before its initiation (18).

The integrity and functioning of the gut microbiota can be influenced by infections, medicine/food supplements and preservatives. Hydrogen sulphide, in optimal concentrations, 
Table I. Clinical studies conducted in the last five years on the effect of mineral waters in gastrointestinal disorders.

\begin{tabular}{lllcr}
\hline Authors & Country & Year & No. of patients & (Refs.) \\
\hline Dupont et al & France & 2014 & 244 & $(27)$ \\
Bothe et al & Slovenia & 2015 & 106 & $(28)$ \\
Naumann et al & Germany & 2016 & 100 & $(29)$ \\
Quattrini et al & Italy & 2017 & Not mentioned & $(25)$ \\
NIH, ClinicalTrials.gov & France & 2017 & 166 & $(30)$ \\
Dupont et al & France & 2019 & 226 & $(31)$ \\
Dragomiretska et al & Ukraine & 2020 & 90 & $(32)$ \\
Constantino et al & Italy & 2020 & Not mentioned & $(33)$ \\
Chavez et al & Brazil & 2020 & 50 & $(34)$ \\
\hline
\end{tabular}

protects the gut flora from the lesions caused by these stressors, stimulate the resorption of the inflammation and cure local wounds (19,20). The $\mathrm{H}_{2} \mathrm{~S}$ concentration in healthy adults varies between 0.3-3.4 mmol/l (19), the higher concentrations being able to cause injury to the intestinal microbiome, disturbing the processes in which it is involved $(21,22)$.

In current practice, sulphurous waters with concentration below $20 \mathrm{mg} / \mathrm{l}$ are used as an internal cure, because $\mathrm{H}_{2} \mathrm{~S}$ has anti-diabetic effects, anti-oxidant properties and antiaging effects, as it inhibits the DNA alteration $(23,24)$.

Alkaline water also results in a decrease in cardio-vascular risks, reducing morbidity and mortality in the elderly population presenting comorbidities (25).

The sulphurous mineral waters above this concentration of $20 \mathrm{mg} / \mathrm{l}$ are only used as external cures (for instance, Pucioasa waters of $1,152 \mathrm{mg} / \mathrm{l})$. In addition, the quantity of water used in sulphurous water crenotherapy is small, $50-100 \mathrm{ml} /$ day up to a maximum of $400 \mathrm{ml} /$ day (1).

Alkaline water having a minimum of $1 \mathrm{~g}$ of salts/liter with a preponderance of the bicarbonate ion and a $\mathrm{pH}$ above 7.0, has proven health-promoting benefits, leading to an equalization of the $\mathrm{pH}$ of the entirebody (26).

The main diseases of the digestive tract treated by crenotherapy are gastro-duodenal dyspepsia, chronic gastritis, duodenitis, gastric or duodenal ulcer, sequelae after surgery, idiopathic gastric dyspepsia, chronic, nonspecific enterocolopathy, chronic constipation, unidentified digestive disorders due to irrational alimentation and stressful conditions $(1,9,17)$.

Although crenotherapy is widespread, the current literature lacks evidence-based data including any exact classification of the different types of mineral waters that can be used as a general guide for the balneology practitioner, or therapeutic protocols available. There is not yet a defined global consensus regarding the indications, therapeutic programs, and their application; all of these differing from one country to another and from one spa to another in terms of crenotherapy. Currently, no international agreements have been established for this type of therapy (10). Romania remains one of the countries with a great variety of natural therapeutic resources, holding $30 \%$ of Europe's supplies. In addition, the richness of spas (160) renders Romania a vital pillar in the development of spa tourism $(1,5,6)$.

\section{Evidence-based literature data focused on the benefit of crenotherapy for GI (gastrointestinal) tract pathologies}

Our review intended to expose the current evidence-based clinical benefit of crenotherapy in gastrointestinal (GI) diseases by analyzing the research reported between 2015 and 2020 on Medline or PubMed online database.

Low functional transit or functional constipation, one of the most common symptoms related to the GI tract, especially in women, has been an issue of crenotherapy indication. Dupont et al demonstrated in a double-blind, randomized, placebo-controlled study on 244 women from France the benefit of crenotherapy with intensely mineralized water rich in magnesium and sulfates in the alleviation of functional constipation during the second week of treatment. The researchers also affirmed a significant decrease in the need for laxative drug use after the same interval (27). Another similar placebo-controlled, double-blind study conducted on 106 patients suffering from functional constipation published by Bothe et al evaluated the efficacy and safety of magnesium and sulfate-rich mineral waters on gut function. The results indicated improved intestinal peristalsis and stool consistency, as well as increased quality of life for patients consuming $300-500 \mathrm{ml}$ of mineral water for six weeks (28).

Naumann et al published in 2016 'Forshende Komplementarmedizin', a double-blind, randomized, placebo-controlled study on the effects of richly mineralized sulfurous water consumed daily for six weeks, and compared the impact to that of carbonated water consumption in a control group. The efficacy of the treatment was observed after three weeks from the baseline by increasing the intestinal motility in the experimental group $(2.02 \pm 2.22$ bowel movements per week) as compared to the control group $(0.88 \pm 1.67$ bowel movements per week) (29).

In 2017, Quattrini et al published an article on the effects of natural mineral waters on health, depending on their physicochemical characteristics. The study conclusions indicated that bicarbonate mineral water neutralizes gastric acid secretion, increasing the $\mathrm{pH}$ of the gastric lumen, stimulating the release of digestive hormones. Chlorinated mineral water stimulates gastric emptying and gastroduodenal peristalsis; the magnesium waters relieve constipation, reducing the associated symptoms. In addition, the functionality of the biliary tract is 
improved by complex mineral waters such as sulfurous-bicarbonate-calcium-magnesium-rich water, due to the anions with choleretic and cholagogue function and the high-magnesium waters favor the relaxation of the Oddi sphincter, allowing the bile to drain, thus improving the activity of the biliary tract (25).

Another ongoing interventional clinical trial, initiated by Bourgeois in 2017, published partial results on the prophylactic effect of rich magnesium mineral water over the hypomagnesemia induced by anti-epidermal growth factor rceptor (EGFR) monoclonal antibodies, indicating a decrease in the incidence of hypomagnesemia as a side effect in such patients. The research was performed on 166 patients undergoing treatment with anti-EGFR monoclonal antibodies for different neoplasia (metastatic colorectal cancer or head and neck cancer), associated with ingestion of mineral water rich in magnesium and poor in sulfates. The mineral water used in this research (Rozana-France) has the highest concentration of magnesium (160 mg/liter) and the lowest sulfate content (30).

Later, in 2019, Dupont et al published a multicenter, double-blind, randomized, controlled study concerning the immediate effect of crenotherapy with magnesium and sulfurous mineral water in functional constipation, confirming the effectiveness and safety of the mineral water use as a first-line curative procedure. The studied patients consumed 1.5 liters/day of Hepar mineral water (France) for 14 days. Researchers confirmed that the mean duration of treatment to obtain constipation relief was shorter in the Hepar mineral water experimental group than in the control group (6.4 vs. 7.3 days, $\mathrm{P}>0.05$ ) (31).

In 2020, Dragomiretska et al published a study in which 90 patients from Ukraine were divided into three equal arms according to the main treatment: i) pharmacologically with proton pump inhibitor, ii) bicarbonate mineral water, and iii) magnesium sulfur bicarbonate mineral water. The results indicated the highest efficacy on dyspepsia and pain syndrome of treatment applied in the third group (32).

Other literature data referring to the effects of magnesium-sulfur mineral waters on functional constipation concluded that mineral waters such as Hepar (France), Ensinger Schiller Quelle-ESQ (Germany), and Donat Mg (Slovenia) represent a natural option for treatment in functional constipation, having a laxative effect, without noticeable side effects $(9,32)$. The authors recommend the daily magnesium consumption of at least $20 \mathrm{mM}$ for a minimum of one week to obtain the mentioned effects (32).

Another article published by Constantino et al in 2020 focused on sulfurous water as a medical resource in certain diseases. The authors concluded that daily ingestion of sulfurous-magnesium mineral water increased gastric secretion and stimulated its evacuation, modulating the motility and releasing the substances accompanying the digesting process (33).

In 2020, a recent study made by Chavez et al highlighted the effects of crenotherapy with alkaline water $(\mathrm{pH}=8.0-10.0)$ administered for five months for gastritis symptom relief. The results showed that besides the beneficial effect of crenotherapy with alkaline water on gastritis symptoms, an improvement in the RNA expression was present, the alkaline water intake significantly increasing the expression of various genes related to the digestion process (34).

\section{Conclusions}

Natural mineral waters represent a valuable therapeutic resource in some circumstances, representing an alternative to pharmacological treatment or an adjuvant, relieving the symptoms of gastrointestinal diseases and increasing the quality of life. According to their composition, therapeutic mineral waters are recommended for consumption as an internal cure in both physiological and pathological conditions, allowing a decrease in drug consumption or the reduction of doses used in classical treatment regimens. Further research focusing on the benefit of crenotherapy is expected, literature being insufficient especially in regards to functional and organic digestive diseases.

\section{Acknowledgements}

Not applicable.

\section{Funding}

Funding information is not applicable.

\section{Availability of data and materials}

All information found in this review is documented by relevant references.

\section{Authors' contributions}

AIS, LM, MD and AdPS conceived and designed the review. FV, AnPS and SIM acquired the data. MGI, AnPS and CV analyzed the data. AIS, FV and SIM validated the results. LM, MGI and AdPS were responsible for the preparation of the original draft. AIS, LM, MR and AnPS were responsible for the final manuscript editing. AdPS, LM and CV supervised the manuscript publication. SIM, CV, AIS and FV revised and made all the corrections required for final manuscript publication. All authors read and approved the final manuscript.

\section{Ethics approval and consent to participate}

Not applicable.

\section{Patient consent for publication}

Not applicable.

\section{Competing interests}

The authors declare that they have no competing interests.

\section{References}

1. Munteanu C: Therapeutic mineral waters. Balneo Res J 2: 52, 2011.

2. Silisteanu SC: Pages of medical history: The balneary-climatic resorts of Romania-ever since the Antiquity to the end of the 19th century. Editura PIM Iaşi, 2016. 
3. Suceveanu AI, Suceveanu AP, Parepa I, Mazilu L, Pantea-Stoian A, Diaconu C, Botea F, Herlea V, Micu SI, Tuta LA, et al: Reducing upper digestive bleeding risk in patients treated with direct oral anticoagulants and concomitant infection with Helicobacter pylori. Exp Ther Med 20: 205, 2020.

4. Oprea C, Ionescu EV Gabriela IM, Almasan RE, Calota N and Iliescu DM: Monitoring and evaluation of patients satisfaction in medical units that use natural factors for treatment. J Environ Prot Ecol 20: 447-452, 2019.

5. Iluta A: Sulphurous mineral waters. Balneo Res J 2: 6-8, 2011.

6. Teleki N and Munteanu L: Spa tourism in Romania. Royal Company, Bucharest, 2012

7. Cociasu E: Hydromineral treatment in internal medicine. Medical Publishing School, Bucharest, p240, 1970.

8. Petraccia L, Liberati G, Masciullo SG, Grassi M and Fraiolo A Water, mineral waters and health. Clin Nutr 25: 377-381, 2006.

9. Munteanu C, Munteanu D and Onose G: Hydrogen sulfide $\left(\mathrm{H}_{2} \mathrm{~S}\right)$-therapeutic relevance in rehabilitation and balneotherapy systematic literature review and meta-analysis based on the PRISMA paradigm. Balneo PRM Res J 12: 176-195, 2021.

10. Cosmoiu M, Munteanu A, Liana G, Pompei I, Gheorghievici G Mustata $\mathrm{M}$ and Tanase I: Physico-chemical, microbiological and pharmacological stability of therapeutic mineral waters. Balneo Res J 3: 68-70, 2012.

11. Munteanu C, Munteanu D and Cinteză D: Sulfurous Waters. Book. Ed. Balneary, Bucharest, 2012.

12. Tudosie MS, Danciulescu Miulescu R, Negulescu V, Ionica M, Stefan SD, Corlan G and Macovei R: Evaluation and modeling of pharmacokinetics of copper ion during hemodialysis. Pharmacy 61: 53-65, 2013.

13. Serban D, Papanas N, Dascalu AM, Stana D, Nicolae VA Vancea G, Badiu CD, Tanasescu D, Tudor C, Balasescu SA and Pantea-Stoian A: Diabetic retinopathy in patients with diabetic foot ulcer: A systematic review. Int J Low Extrem Wounds 20 98-103, 2021.

14. Piuri G, Zocchi M, Della Porta M, Ficara V, Manoni M, Zuccotti GV, Pinotti L, Maier JA and Cazzola R: Magnesium in obesity, metabolic syndrome, and type 2 diabetes. Nutrients 13: 320, 2021.

15. Serban D, Socea B, Balasescu SA, Badiu CD, Tudor C, Dascalu AM, Vancea G, Spataru RI, Sabau AD, Sabau D and Tanasescu C: Safety of laparoscopic cholecystectomy for acute cholecystitis in the elderly: A multivariate analysis of risk factors for intra and postoperative complications. Medicine (Kaunas) 57: 230, 2021.

16. Șerban D, Spătaru RI, Vancea G, Bălășescu SA, Socea B, Tudor C and Dascălu AM: Informed consent in all surgical specialties: From legal obligation to patient satisfaction. Rom J Leg Med 28 : 317-321, 2020 .

17. Gheorghe G, Stoian AP, Gaman MA, Socea B, Neagu TP Stanescu AMA, Bratu OG, Mischianu DLD, Suceveanu AI and Diaconu CC: The benefits and risks of antioxidant treatment in liver diseases. Rev Chim 70: 651-655, 2019.

18. Cinteză D, Lăzărescu D, Brăilescu C, Bunescu I, Covaleov A and Diaconescu S: Balneary Guide. 1st edition. National Institute of Rehabilitation, Physical Medicine and Balneoclimatology, Bucharest, 2011.

19. Dordević D, Jančíková S, Vítězová $M$ and Kushkevych I: Hydrogen sulfide toxicity in the gut environment: Meta-analysis of sulfate-reducing and lactic acid bacteria in inflammatory processes. J Adv Res 27: 55-69, 2020.
20. Buret AG, Allain T, Motta JP and Wallace JL: Effects of hydrogen sulfide on the microbiome: From toxicity to therapy. Antioxid Redox Signal: Apr 21, 2021 (Epub ahead of print).

21. Carbonero F, Benefiel AC, Alizadeh-Ghamsari AH and Gaskins HR: Microbial pathways in colonic sulfur metabolism and links with health and disease. Front Physiol 3: 448, 2012

22. Dostal Webster A, Staley C, Hamilton MJ, Huang M, Fryxell K, Erickson R, Kabage AJ, Sadowsky MJ and Khoruts A: Influence of short-term changes in dietary sulfur on the relative abundances of intestinal sulfate-reducing bacteria. Gut Microbes 10: 447-457, 2019.

23. Magro M, Corain L, Ferro S, Baratella D, Bonaiuto E, Terzo M, Corraducci V, Salmaso L and Vianello F: Alkaline water and longevity: A murine study. Evid Based Complement Alternat Med 2016: 3084126, 2016.

24. Lilios G, Apetroaei MR and Dantes E: Environmental factors influence on human health-alkaline water usage. J Environ Prot Ecol 16: 1612-1619, 2015.

25. Quattrini S, Pampaloni B and Brandi ML: Natural mineral waters: Chemical characteristics and health effects. Clin Cases Miner Bone Metab 13: 173-180, 2016.

26. Yehia HMAS and Said SM: Drinking water treatment: $\mathrm{pH}$ adjustment using natural physical field. J Biosci Med 9: 55-66, 2021.

27. Dupont C, Campagne A and Constant F: Efficacy and safety of a magnesium sulfate-rich natural mineral water for patients with functional constipation. Clin Gastroenterol Hepatol 12: 1280-1287, 2014

28. Bothe G, Coh A and Auinger A: Efficacy and safety of a natural mineral water rich in magnesium and sulphate for bowel function: A double-blind, randomized, placebo-controlled study. Eur J Nutr 56: 491-499, 2017.

29. Naumann J, Sadaghiani C, Alt F and Huber R: Effects of sulfate-rich mineral water on functional constipation: A double-blind, randomized, placebo-controlled study. Forsch Komplementmed 23: 356-363, 2016

30. U.S. National Library of Medicine (NIH): Prophylax is of magnesium-rich mineral water to prevent hypomagnesemia induced by an anti-EGFR (OPTIMAG) (OPTIMAG). ClinicalTrials.gov Identifier: NCT03146338. NIH, Bethesda, MD, 2017.

31. Dupont C, Constant F, Imbert A, Hébert G, Zourabichvili O and Kapel N: Time to treatment response of a magnesium- and sulphate-rich natural mineral water in functional constipation. Nutrition 65: 167-172, 2019.

32. Dragomiretska NV, Babov KD, Gushcha SG, Zabolotna IB, Plakida AL, Izha AN, Babova IK, Nasibullin BA and Trubka IA: Application of mineral waters in the complex treatment of patients with gastroesophageal reflux disease. Minerva Gastroenterol Dietol 66: 225-237, 2020

33. Constantino M, Izzo V, Conti V, Manzo V, Guida $\mathrm{A}$ and Filippelli A: Sulphate mineral waters: A medical resource in several disorders. J Tradit Complement Med 10: 320-326, 2020.

34. Chavez JR, de Souza CRT, Modesto AAC, Moreira FC, Teixeira EB, Sarraf JS, Allen TSR, Araújo TMT and Khayat AS: Effects of alkaline water intake on gastritis and miRNA expression (miR-7, miR-155, miR-135b and miR-29c). Am J Transl Res 12: 4043-4050, 2020 